\title{
Prevalence of Schistosomiasis Infection among Young Children Aged 5 to 17 Years in Kilosa District, Tanzania: A 3 Year Retrospective Review
}

\section{Nicholas J Kavana}

Department of Parasitology and Entomology, St. Francis University College of Health and Allied Sciences, Ifakara, Tanzania

*Corresponding author: Nicholas J Kavana, Department of Parasitology and Entomology, St. Francis University College of Health and Allied Sciences, P.O Box 175, Ifakara, Tanzania, Tel: +81-980522719; E-mail: nkavana@yahoo.com

Received date: January 18, 2018; Accepted date: February 10, 2018; Published date: February 20, 2018

Copyright: @ 2018 Kavana NJ. This is an open-access article distributed under the terms of the Creative Commons Attribution License, which permits unrestricted use, distribution, and reproduction in any medium, provided the original author and source are credited.

\begin{abstract}
This study was aimed at determining the prevalence of schistosomiasis in children aged 5-17 years in Kilosa district over a 3 year period. A retrospective study using records of laboratory data from laboratory record books of the selected health facilities in four wards in Kilosa district. Samples of urine and stool submitted by young children to the laboratories of health facilities between 2014 and 2016 were recorded.

A total of 702 samples were collected from the laboratory records books involving their age, sex and schistosome species. Of the 702 individuals, 541 were examined for urinary schistosomiasis and 161 for intestinal schistosomiasis; $31(5.7 \%)$ were infected with S. haematobium and $11(6.8 \%)$ with S. mansoni respectively.

However, the overall prevalence of schistosomiasis was $6.27 \%$ in the study area. Males had prevalence for $S$. haematobium was $1.00 \%$ and S. mansoni was $2.35 \%$ while females had prevalence for S. haematobium was $3.96 \%$ and S. mansoni was $1.00 \%$. Children of age group 13-17 years were infected with both species, S. haematobium was $5.11 \%$ and $S$. mansoni was $1.99 \%$. Ruhembe ward had highest prevalence in both species, $S$. haematobium was $8.62 \%$ and $S$. mansoni was $5.17 \%$ respectively. The findings confirm that schistosomiasis is a public health problem in the district.
\end{abstract}

Keywords: Schistosomiasis; S. haematobium; S. mansoni; Prevalence; Children

\section{Introduction}

Human schistosomiasis also called bilhazia, is a freshwater snail transmitted disease caused by infection from one of the several species of parasitic trematodes of the genus schistosoma, which lives in the bloodstream of human. It is second to malaria in human impact among tropical diseases and the third (after malaria and intestinal helminthiasis) in global parasitism. Schistosomiasis is the most devastating prevalent parasitic disease due to morbidity and mortality for developing countries in Africa, South America, the Caribbean, the Middle East and Asia [1]. The World Health Organization (WHO) regards the disease as a neglected tropical disease, with an estimated 732 million persons being vulnerable to infection worldwide in renowned transmission areas. The WHO further estimated that schistosome infections and geohelminths accounts for over $40 \%$ of the world tropical disease burden with exclusion of malaria. Prevalence of schistosomiasis, at present is still high in sub-Saharan Africa. Approximately 120 million individuals in sub-saharan africa have schistosomiasis-related symptoms while about 20 million undergo hardship as a result of chronic presentations of the disease. The distribution of the disease is focal and often restricted to areas with peculiar ecology which favors its transmission. The disease is associated with considerable morbidity and mortality in the developing world [2].

Schistosoma mansoni is the chief cause of clinical abnormalities such as hepatomegaly, spleenomegaly and periportal fibrosis in various sub-saharan Africa countries. A study in northern Ethiopia in Alamata district revealed an alarming $73.9 \%$ prevalence of schistosoma infection, with presentation of $3.7 \%$ hepatomegaly, $7.4 \%$ spleenomegaly and $12.3 \%$ periportal fibrosis. Schistosomiasis due to $S$. mansoni is on top of the list of the causes of pulmonary hypertension worldwide, especially in areas where schistosomiasis is endemic. A survey of school children aged 5-19 years in Mbita and some Islands close to Lake Victoria in Kenya revealed that the communities were highly endemic for $S$. mansoni infection with prevalence as high as $60.5 \%$ [3-5]. An investigative study of in-school and not in-school children aged 6-15 years living in communities along the Tono Irrigation Canal in North Ghana revealed a prevalence of $33.2 \%$ of $S$. haematobium infection and a $19.8 \%$ for $S$. mansoni. It was also observed that there was higher infection rate in male children compared to their female counterparts, which might be due to longer period of contact with contaminated water.

A nation-wide survey of the prevalence of Schistosoma infections and soil helminthes in school children from Mozambique reported a prevalence of $47.0 \% S$. haematobium infection and $1.0 \% S$. mansoni infection. Further observation from this study showed that infection increases with age, the age group 10-14 years having the highest prevalence of $S$. haematobium infection [4]. It was also observed that across the districts, male children had higher prevalence compared to their female counterparts. The high prevalence of schistosomiasis was attributed to inadequate water supply in the districts, poor sanitation, and a low level of socioeconomic development in most parts of Mozambique. A study done at Barombi Kotto focus, South West Cameroun, revealed an alarming $69.17 \%$ prevalence of $S$.haematobium infection confirming high endemicity in the area. It was noted that 
Page 2 of 5

most lakes in the area were habitats for the B. globosus intermediate host required for disease transmission. A study carried out in Agboville, Coted'Ivoire among school-aged children showed a very high prevalence of $85.3 \%$ and $53.8 \%$ for $S$. haematobium and $S$. mansoni respectively [6-9].

In Tanzania both the urogenital and intestinal forms of the disease are endemic in all administrative regions. The Schistosoma haematobium, is widespread, and transmission tends to coincide with the rainy season. As the number and level of water bodies increase, female Bulinus snails lay large numbers of eggs that mature and start shedding cercariae shortly after the rainy season [10]. The intestinal parasite, $S$. mansoni, is more focally endemic, and its transmission follows a similar pattern. Year-round transmission of both forms of schistosomiasis occurs in permanent water bodies along the shores of Lake Victoria, in irrigation schemes, and near hydroelectric dams $[11,12]$. The prevalence of schistosomiasis countrywide is $53.3 \%$. Children of age group 5-17 years are usually highly vulnerable group and represent infection status in the population. These children tend to wash and bath in canal or pond water infested with the parasites. The aim of this study was to determine the prevalence of schistomiasis infection among young children aged between 5-17 years in Kilosa district, Morogoro region, Tanzania over a period between 2014 and 2016 [13-15].

\section{Methodology}

\section{Study area}

Kilosa district is one of the Districts in Morogoro Region. It lies within longitudes $366^{\prime} 30^{\prime \prime}$ and $37^{\prime} 30^{\prime \prime} \mathrm{E}$ and latitudes 5'55" and 7'53"S. and at an altitude of $511 \mathrm{~m}$ above sea level has an estimated land area of $12,394 \mathrm{~km}^{2}$. It has a population of 438,175 people of these 219,797 females and 218,378 males this is according to population census of 2012.

\section{Study design}

A retrospective study using laboratory record results of urine and stool samples from health facilities of four wards in the district between 2014 and 2016.

The study population comprised young children aged from 5 years to 17 years old who went to the health facilities and their urine and stool samples were examined and recorded in the laboratory books.

\section{Sampling technique}

The study area was obtained by multistage cluster sampling from the districts of Morogoro region. Kilosa district was randomly selected through picking a paper with written names of the 6 districts of the region. The 7 divisions in Kilosa district were written on papers and Ruaha division was randomly selected. Then the same procedure was carried out to get the 4 wards (Ruaha, Ruhembe, Kidodi, Mikumi) from a total of 5 wards in the division. Health facilities in the selected villages were selected basing to their accessibility.

\section{Data collection tools and procedures}

Laboratory records from January through December 2014, 2015 and 2016 years were obtained from each health facility involved in the study. Only urine and stool sample results records of individuals with age range 5-17 years were recorded from the record books.

\section{Data analysis}

The data obtained were analysed using Statistical Package for Social Sciences (SPSS) version 20) into simple percentiles.

\section{Ethical issues}

The proposal of the study was approved by the St. Francis University College of Health and Allied Sciences Ethical Committee. A letter was written to the District Executive Director (DED) of Kilosa district then to the District Medical Officer (DMO) of Kilosa, permission was granted to go to the local authority leaders and in-charges of health facilities which were involved in the studyConfidentiality and privacy were considered as no names were recorded. Information obtained were used for research purpose only.

\section{Results}

\section{Socio-demographic characteristics of the sample population in Kilosa district}

A total of 702 samples of urine and stool were submitted to the laboratories involved in the study. The individuals of the age group 5-8 years were $183(26.07 \%)$, 9-12 years were $167(23.79 \%)$ and $13-17$ years were $352(50.14 \%)$. Among the individuals, 432 (61.54\%) were female and $270(38.46 \%)$ were male. Distribution from the wards, Ruhembe 116 (16.52\%), Ruaha $311(44.30 \%)$, Kidodi 0 (0\%) and Mikumi 275 (39.17\%) as shown (Table 1$)$.

\begin{tabular}{|c|c|c|}
\hline Age & No. examined & Percent (\%) \\
\hline $5-8$ & 183 & 26.07 \\
\hline $9-12$ & 167 & 23.79 \\
\hline $13-17$ & 352 & 50.14 \\
\hline Total & 702 & 100 \\
\hline \multicolumn{3}{|l|}{ Sex } \\
\hline Female & 432 & 61.54 \\
\hline Male & 270 & 38.46 \\
\hline Total & 702 & 100 \\
\hline \multicolumn{3}{|l|}{ Ward } \\
\hline Ruhembe & 116 & 16.52 \\
\hline Ruaha & 311 & 44.30 \\
\hline Kidodi & 0 & 0 \\
\hline Mikumi & 275 & 39.17 \\
\hline Total & 702 & 100 \\
\hline
\end{tabular}

Table 1: Socio-demographic distribution of the sample population in Kilosa district.

\section{Prevalence of Schistosoma haematobium and Schistosoma mansoni among young children}

Between 2014 and 2016 a total of 702 individuals were examined stool and urine, 541 (77.0\%) were examined urine for $S$. haematobium 
Citation: Kavana NJ (2018) Prevalence of Schistosomiasis Infection among Young Children Aged 5 to 17 Years in Kilosa District, Tanzania: A 3 Year Retrospective Review. J Trop Dis 6: 255. doi:10.4172/2329-891X.1000255

Page 3 of 5

and $161(22.93 \%)$ was stool for $S$. mansoni. Out of these $31(5.73 \%)$ were infected with $S$. haematobium and $11(6.83 \%)$ with $S$. mansoni species.

\section{Sex distribution of Schistosoma haematobium and Schistosoma mansoni among young children}

During the period 2014 through 2016 years a total of 702 individuals were examined for S. haematobium and S. mansoni species, $404(57.55 \%)$ were female and 298 (42.45\%) were male. The total individuals infected with $S$. haematobium and $S$. mansoni were 42. Females infected with $S$. haematobium were $16(3.96 \%)$ and $S$. mansoni were $4(1.00 \%)$. Males infected with $S$. haematobium were 15 $(5.03 \%)$ and $S$. mansoni were 7 (2.35\%) (Table 2).

\begin{tabular}{|c|c|c|c|c|}
\hline Schistosoma sp. & Sex & No. examined & No. infected & Percent (\%) \\
\hline S.haematobium & Female & 404 & 16 & 1.96 \\
\hline & Male & 298 & 31 & 73.81 \\
\hline Total & & 702 & 4 & 1.00 \\
\hline S.mansoni & Female & 404 & 7 & 2.35 \\
\hline
\end{tabular}

Table 2: Sex distribution of Schistosoma haematobium and Schistosoma mansoni among young children.

\section{Age distribution of Schistosoma haematobium and} Schistosoma mansoni among young children

The results of $S$. haematobium infection according to age distribution, 5-8 years was 6 (3.28\%), 9-12 years was $7(4.19 \%)$ and
13-17 years was 18 (5.11\%). S. mansoni infection, 5-8 years was 3 (1.64\%), 9-12 years was $1(0.60 \%)$ and $13-17$ years was $7(1.99 \%)$ (Table 3).

\begin{tabular}{|l|l|l|l|l|}
\hline Schistosoma sp. & Age & No. examined & No. infected & Percent (\%) \\
\hline S. haematobium & $5-8$ & 183 & 6 & 3.28 \\
\hline & $9-12$ & 167 & 7 & 4.19 \\
\hline Total & $13-17$ & 352 & 18 & 5.11 \\
\hline S. mansoni & & 702 & 31 & 12.58 \\
\hline & $5-8$ & 183 & 3 & 1.64 \\
\hline & $9-12$ & 167 & 1 & 0.60 \\
\hline Total & $13-17$ & 352 & 7 & 1.99 \\
\hline
\end{tabular}

Table 3: Age distribution of Schistosoma haematobium and Schistosoma mansoni among young children.

Distribution of Schistosoma haematobium and Schistosoma mansoni in wards

S. haematobium infection for each ward, Ruhembe ward was 10 (8.62\%), Ruaha 8 (2.57\%), Kidodi $0(0 \%)$ and Mikumi $13(4.73 \%)$. $S$. mansoni infection, Ruhembe 6 (5.17\%), Ruaha 1 (0.32\%), Kidodi 0 (0\%) and Mikumi $4(1.45 \%)$ as shown (Table 4$)$.

\begin{tabular}{|l|l|l|l|l|}
\hline Schistosoma sp. & Wards & No. examined & No. infected & Percent (\%) \\
\hline S. haematobium & Ruhembe & 116 & 10 & 8.62 \\
\hline & Ruaha & 311 & 8 & 2.57 \\
\hline & Kidodi & 0 & 0 & 0 \\
\hline
\end{tabular}


Page 4 of 5

\begin{tabular}{|l|l|l|l|l|}
\hline & Mikumi & 275 & 13 & 4.73 \\
\hline Total & & 702 & 31 & 15.92 \\
\hline S. mansoni & Ruhembe & 116 & 6 & 5.17 \\
\hline & Ruaha & 311 & 1 & 0.32 \\
\hline & Kidodi & 0 & 0 & 0 \\
\hline Total & Mikumi & 275 & 4 & 1.45 \\
\hline
\end{tabular}

Table 4: Prevalence of Schistosoma haematobium and Schistosoma mansoni among young children by wards.

\section{Discussion}

Prevalence of urinary and intestinal schistosomiasis among young children continues to be a major public health concern in tropical countries especially in Tanzania. Schistosoma infection cause chronic infection which negatively affects all aspects of the children health, nutrition and learning. Schistosoma infection during childhood cause substantial growth retardation and anemia also cause structural abnormalities of urinary tract. The transmission cycle requires contamination of surface water by excreta or urine and fresh water snail as an intermediate host and human water contact.

In the present study, the prevalence of schistosomiasis infection in Kilosa district is $6.27 \%$ with rate of urinary schistosomiasis and intestinal schistosomiasis prevalence rate being $4.42 \%$ and $1.57 \%$ respectively. The present prevalence of schistosomiasis in Kilosa district has significantly decreased compared to the previous prevalence of $53.4 \%$. The prevalence of $S$. haematobium in the present study is $4.41 \%$ it is lower compared to that reported in Mozambique with prevalence of $47.0 \%$ [16-18]. The prevalence of $S$. mansoni was observed to be lower than that reported in the nearby East African countries the prevalence in pre-school children was 44.3 and $16 \%$ respectively on the shores of Lake Albert and Lake Victoria in Uganda and $14 \%$ in Lake Victoria in Kenya.

In relation to sex, the prevalence of $S$. mansoni infection in male $(2.35 \%)$ is higher than in females $(1.00 \%)$ while the prevalence of $S$. haematobium in females (3.96\%) is higher than in males $(1.00 \%)$ [19-22]. The difference in prevalence rates may be influenced by peculiar ecological characteristics and level of contact of individuals with water bodies and the degree or exposure to infective schistosoma cercariae in different locations. The lower prevalence of $S$. haematobium $(1.00 \%)$ in males in the present study is lower than the prevalence of $58.1 \%$ reported for pre-school children in Rural Community near Abeokuta, Nigeria.

The high prevalence of $S$. haematobium $(5.11 \%)$ among the age group 13-17 years in this study is lower than the findings of Dakul et al. who reported the highest prevalence $65.8 \%$ among the age group 10-14 years in Lankaku-Namu district, Quan'an- Plateau State [23,24]. The prevalence observed in the present study for $S$. mansoni is lower than that reported in children aged 5-19 years in Mbita and some Islands close to Lake Victoria in Kenya which revealed high prevalence of $S$. mansoni $60.5 \%$.

Prevalence of schistosoma infection among wards in Kilosa district involved in the present study, Ruhembe ward had highest prevalence of both $S$. haematobium $(8.62 \%)$ and $S$. mansoni $(5.17 \%)$ than the other three wards [25]. This could be attributed to the behavior of this population group living in this ward their repeated contact with contaminated water, lack of safe water for bathing, poor sanitation and low level of socio-economic development. It has been reported that increased water contact activities such as fishing, bathing and farming were associated with an increased risk of being infected with $S$. haematobium and $S$. mansoni species [26].

\section{Conclusion}

Schistosomiasis has been of great health concern globally and mostly in communities of sub-Saharan Africa including Tanzania. Although there is a mass drug administration program (MDAP) still the zero percent goal has not been achieved. This study has demonstrated that the overall prevalence of schistosomiasis in Kilosa district, Morogoro, Tanzania is $6.27 \%$ this shows that the problem still existing.

Appropriate intervention and health education for the community are required for the control and prevention of schistosomiasis in Kilosa district.

It is imperative to further conduct a more comprehensive epidemiological survey on urinary and intestinal schistosomiasis so as to identify all high risk factors for the infection.

\section{Acknowledgement}

The author would like to thank St. Francis University College of Health and Allied Sciences for funding this project. Thanks go to the District Executive Director, Kilombero District for giving permission to carry out this study. Also thanks go to MD 3 students who were involved in data collection for this study.

\section{References}

1. Abebe N, Erko B, Medhin G, Berhe N (2014) Clinico-epidemiological study of Schistosomiasis mansoni in Waja-Timuga, District of Almata, Northern Ethiopia. Parasites \& Vectors 7: 158.

2. Anto F, Asoala V, Adjuik M (2013) Water contact activities and prevalence of schistosomiasis infection among school age children in communities along an irrigation scheme in rural Northern Ghana. J Bacter Parasit 4: 177.

3. Augusto G, Nal'a R, Casmo V, Sabonete A, Mapaco L, et al. (2009) Geographic distribution and prevalence of schistosomiasis and soiltransmitted elminthes among school children in Mozambique. Amer J Trop Med Hyg 81: 799-803. 
Citation: Kavana NJ (2018) Prevalence of Schistosomiasis Infection among Young Children Aged 5 to 17 Years in Kilosa District, Tanzania: A 3 Year Retrospective Review. J Trop Dis 6: 255. doi:10.4172/2329-891X.1000255

Page 5 of 5

4. Chitsulo L, Engels D, Montresor A, Savioli L (2000) The global status of schistosomiasis and its control. Acta Tropica 77: 41-51.

5. Dakul DA, Onwuliri COE, Anyanwu GI, Imander NG (2001) A longitudinal study of Schistosoma haematobium infection in Quaan-pan local government area of Plateau State. J Pest Vect Manag 3: 225-230.

6. Dawet A, Benjamin CB, Yakubu DP (2012) Prevalence and intensity of Schistosoma haematobium residence of Gwong and Kabong in Jos North Local Government Area in Plateau State. Int J Trop Med 7: 69-72.

7. Ekpo UF, Laja DA, Oluwole AS, Sam-Wobo SO, Mafiana CF, et al. (2010) Urinary schistosomiasis among Pre-school Children in a Rural Community near Abeokuta, Nigeria. Parasites Vectors 3: 10.

8. Hotez PJ, Fenwick A (2009) Schistosomiasis in Africa: An emerging tragedy in our new global health decade. PloS Neglected Tropica Diseases 3: 485.

9. Humphrey DM, Rebecca W, Gerald MM, Maria Z, Emmanuela EA, et al (2010) Intestinal Schistosomiasis among school children in endemic area of north western Tanzania. J Rur Trop Pub Healt, pp: 53-60.

10. Kinung'hi SM, Magnussen P, Kaatano GM, Kishamawe C, Vennervald BJ, et al. (2014) Malaria and helminth co-infections in school and pre-schoo children: a cross-sectional study in Magu district, north-western Tanzania. PLoS One 9: 86510.

11. Kloos H, Gazzinelli A, Vanzuyl P (1998) Microgeography patterns of schistosomiasis and water contact behavior example from Africa and Brazil. Mem Inst Oswaldo Cruz 93: 37-50.

12. Lapa M, Dias B, Jardim C, Fernandes CJC, Dourado PMM, et al. (2009) Cardiopulmonary manifestations of hepatosplenic schistosomiasis. Circulation 119: 1518-1523.

13. Lengeler C, DeSavigny DO, Mshinda H, Mayombana C, Tayari S, et al. (1991) Community based questionnaires and Health statistics as tools for the cost efficient identification at risky of urinary schistosomiasis. Int Epidem 20: 796-807.

14. Lwambo NJ, Siza JE, Brooker S, Bundy DA, Guyatt H, et al. (1999) Patterns of concurrent Hookworm infection and schistosomiasis in schoolchildren in Tanzania. Trans Royal Soc Trop Med Hyg 93: 497-502.

15. Mazigo HD, Nuwaha F, Kinung'hi SM, Morona D, de Moira AP, et al. (2012) Epidemiology and control of human schistosomiasis in Tanzania Parasites \& Vectors 5: 274
16. Müller I, Coulibaly JT, Fürst T, Knopp S, Hattendorf J, et al. (2011) Effect of schistosomiasis and soil-transmitted helminth infections on physical fitness of school children in côte d'ivoire. PLoS Neglected Tropical Diseases 5: e1239.

17. https://dhsprogram.com/pubs/pdf/FR243/FR243[24June2011].pdf

18. Nkengazong L, Njiokou F, Asonganyi T (2013) Two years impact of single praziquantel treatment on urinary schistosomiasis in the Barombi Kotto focus, South West Cameroon. J Parasitol Vector Biol 5: 83-89.

19. Odiere MR, Rawago FO, Obok M (2012) High prevalence of schistosomiasis in Mbita and its adjacent islands of Lake Victoria, Western Kenya. Parasites \& Vectors 5: 278.

20. Pukuma SM, Sale HL, Njila HL, Dibal M (2006) Urinary schistosomiasis in primary school pupils of Shelleng town, Adamawa State, Nigeria. J Pests Dis Vect Manag 7: 445-448

21. Rudge JW, Stothard JR, Basáñez MG, Mgeni AF, Khamis IS, et al. (2008) Micro-epidemiology of urinary schistosomiasis in Zanzibar: Local risk factors associated with distribution of infections among schoolchildren and relevance for control. Acta Tropica 105: 45-54.

22. Sarkinfada F, Oyebanji AA, Sadiq IA, Ilyasu Z (2009) Urinary schistosomiasis in the Danjarima community in Kano, Nigeria. J Infect Dev Ctries 3: 452-457.

23. Singh K, Muddasiru D, Singh J (2016) Current status of schistosomiasis in Sokoto, Nigeria. Para Epid Cont 1: 239-244.

24. Sousa-Figueiredo JC, Pleasant J, Day M, Betson M, Rollinson D, et al. (2010) Treatment of intestinal schistosomiasis in ugandan pre-school children: best diagnosis, treatment efficacy and side-effects and an extended praziquantel dosing pole. Int Health 2: 103-113.

25. Steinmann P, Keiser J, Bos R, Tanner M, Utzinger J, et al. (2016) Schistosomiasis and water resources development: systematic review, meta-analysis and estimates of people at risk. Lancet Infect Dis 6: 411-425.

26. Verani JR, Abudho B, Montgomery SP, Mwinzi PNM, Shane HL, et al. (2011) Schistosomiasis among young children in Usoma, Kenya. Amer J Trop Med Hyg 84: 787-791. 